\title{
Aetiologies of Vaginal Discharge among Women Presented with Cervical Abnormalities: Experiences at a Tertiary Care Hospital
}

\author{
Rahman $\mathrm{D}^{1}$, Adhikary $\mathrm{A}^{2}$, Hussein $\mathrm{S}^{3}$
}

\begin{abstract}
Background: Vaginal discharge is a common gynaecological problem worldwide. It is a common presentation of different gynaecological diseases. Objective: The aim of the study was to find out the aetiological factors responsible for vaginal discharge among the women presented with cervical pathology. Methodology: This cross sectional study was carried out in patients complaining of vaginal discharge attending at Gynaecology department (GOPD) in Dhaka Medical College Hospital (DMCH), Dhaka from March'2006 to October'2006. Required tests were carried out in the Department of Microbiology and Department of Pathology at Dhaka Medical College, Dhaka. Data were obtained by history taking, physical examination and relevant investigations. Results: Cervical pathology was associated in $64.0 \%$ of patients complaining of vaginal discharge. Out of these, most common are cervicitis $(48.0 \%)$ carcinoma of cervix $(8.0 \%)$ cervical erosion $(4.0 \%)$ endocervical polyp $(2.0 \%)$ and old cervical tear $(2.0 \%)$. Other associated aetiologies of abnormal vaginal discharge were bacterial vaginosis $(12.0 \%)$ candidiasis $(10.0 \%)$ trichomoniasis $(10.0 \%)$. Conclusion: Vaginal discharge is a manifestation of many cervical pathology including carcinoma. Therefore, proper evaluation is needed in all patients complaining of vaginal discharge before treatment. [J Shaheed Suhrawardy Med Coll, 2013;5(1):31-34]
\end{abstract}

Key words: Vaginal discharge, cervical pathology, aetiologies, vaginal candidiasis,

Received: March 2012; Revised: March 2013; Accepted: May 2013

\section{Introduction}

Vaginal discharge is a frequent complaint of women in day to day gynaecologic clinic ${ }^{1}$. Vaginal discharge is a common presentation of different gynecological diseases including carcinoma cervix and this is a major health concern ${ }^{2}$. Its proper evaluation has not been developed at the national level and is only practiced sporadically by few institutes, tertiary level hospitals and private practitioners ${ }^{3}$. Bangladesh has a comprehensive health infrastructure which offers the possibility of introducing national programme for evaluation of risk factors and causes of vaginal discharge and their proper treatment ${ }^{4}$.

Physiological discharge is normally seen at vulva and vagina varies in amount and character with ovarian function ${ }^{5}$.The amount of vaginal discharge ordinarily present in the adult is such that the introitus feels comfortably moist; however, this is not enough to stain the underclothing. It is normally increased to the extent of becoming noticeable at the time of ovulation when there is 'ovulation cascade' from the cervix; during pregnancy when there is an increase in vaginal and cervical discharges and during sexual excitement when there is an outpouring of Bartholin's secretion onto the vulva ${ }^{6}$. Pathological discharge is excess of normal which may be leucorrhoea or physiological excessive discharge from cervix and vagina ${ }^{7-8}$. It may be due to infections like vulvovaginitis due to trichomoniasis, moniliasis, bacterial vaginosis, cervicitis $^{9}$. It may be also due to some local causes due to myomatous polyp, cervical ectropion or tear, genital malignancy, fistulae ${ }^{10}$. Sometimes foreign body such as forgotten pessary, tampon, mechanical irritation may cause excessive discharge ${ }^{11}$.

Diagnosis of various causes of vaginal discharge are done by detailed history taking, physical examination and investigations ${ }^{12}$. This study was undertaken to find out the aetiologies of vaginal discharge among the women presented with cervical abnormalities.

\section{Methodology}

This cross sectional study was carried out among women complaining of vaginal discharge attending in Gynaecology Outpatient Department (GOPD) at Dhaka Medical College Hospital (DMCH), from March'2006 to October'2006.

1. Dr. Dalia Rahman, Junior Consultant, Department of Obstetrics \& Gynaecology, Shaheed Suhrawardy Medical College \& Hospital, Dhaka

2. Dr. Alpana Adhikary, Medical Officer, Department of Obstetrics \& Gynaecology, Shaheed Suhrawardy Medical College \& Hospital, Dhaka

3. Dr. Sabina Hussein, Associate Professor, Department of Obstetrics \& Gynaecology, Shaheed Suhrawardy Medical College, Dhaka

\section{Correspondence}

Dr. Dalia Rahman, Junior Consultant, Department of Obstetrics \& Gynaecology, Shaheed Suhrawardy Medical College \& Hospital, Sher-E-Bangla Nagar Dhaka-1207, Bangladesh; Email: shaliabd1@gmail.com; Cell No.: +8801711104479

Conflict of interest: No conflict of interest

Financial Support: None

Contributions by authors: Dr. D Rahman contributed from protocol writing upto article write up. Dr. A. Adhikary \& Dr. S. Hussein reviewed and corrected the paper. 
Married women of 15-60 years of age were included in this study. Menstruating women, pregnant women and women with total hysterectomy were excluded from this study. After obtaining informed verbal consent, proper history taking and physical examination were performed. During per speculum examination, high vaginal swab, endocervical swab and pap's smear were taken and was sent to the laboratory at the Department of Microbiology and Pathology at DMCH for appropriate test. Microscopic examination, culture and Whiff test were done. If there was gross lesion of cervix; biopsy was taken and sent for histopathology at the Department of Pathology. Complete blood count (CBC) and ultrasonography (USG) of lower abdomen were done as supportive investigation. All the data ware recorded in a predesigned structured questionnaire. Statistical analysis was done with SPSS (Statistical Package for the Social sciences) software. Qualitative data was expressed as frequency with percentage and quantitative data expressed as mean with standard. The association was measured by Chi-Square test. P Value $<0.05$ was taken as statistically significant.

\section{Results}

A total number of 50 cases were studied. Among 50 patients with vaginal discharge, majority $(60 \%)$ belonged to the age group of $26-35$ years, $60 \%$ patients were illiterate, $30 \%$ had primary school education and only $10 \%$ had secondary education and majority $\left(90^{\circ} \%\right)$ were multipara (Table 1$)$.

Table 1: Background characteristics of the study population $(\mathbf{n}=\mathbf{5 0})$

\begin{tabular}{lccc}
\hline General Characteristics & Frequency & Percentage \\
\hline Age & $16-25$ & 05 & 10.0 \\
& $26-35$ & 30 & 60.0 \\
\multirow{4}{*}{ Education } & $>35$ & 15 & 30.0 \\
& Illiterate & 30 & 60.0 \\
& Primary & 15 & 30.0 \\
Parity & Secondary & 05 & 10.0 \\
& Primipara & 05 & 10.0 \\
& Multipara & 45 & 90.0 \\
\hline
\end{tabular}

A total of $52.0 \%$ had history of menstrual regulation (MR) or unsafe abortion, whereas $34.0 \%$ had history of puerperal sepsis (Table 2).

Table 2: Relationship between Previous Pregnancy Termination Event and Vaginal Discharge $(n=50)$

\begin{tabular}{lcc}
\hline $\begin{array}{l}\text { Pregnancy Termination } \\
\text { Event }\end{array}$ & Frequency & Percentage \\
\hline MR /abortion & 26 & 52.0 \\
Puerperal sepsis & 17 & 34.0 \\
No positive history & 7 & 14.0 \\
Total & $\mathbf{5 0}$ & $\mathbf{1 0 0 . 0}$ \\
\hline
\end{tabular}

* $\mathrm{MR}=$ menstrual regulation

Out of 50 patients, most of them $(40.0 \%)$ were nonusers, $20.0 \%$ patients used oral pills only, rest $40.0 \%$ of the patients used other method either singly or in combination (Table 3 ).
Table 3: Relationship between Contraceptives and Vaginal Discharge $(n=50)$

\begin{tabular}{lcc}
\hline Contraceptives & Frequency & Percentage \\
\hline OCP & 10 & 20.0 \\
Barrier & 5 & 10.0 \\
IUCD & 4 & 8.0 \\
Injections & 7 & 14.0 \\
Tubectomy & 4 & 8.0 \\
Nonuser & 20 & 40.0 \\
Total & $\mathbf{5 0}$ & $\mathbf{1 0 0}$ \\
\hline
\end{tabular}

*OCP $=$ Oral Contraceptive Pill

*IUCD $=$ Intrauterine Contraceptive Device

Study showed that cervical pathology was associated in $64.0 \%$ of patients with vaginal discharge. Out of these, chronic cervicitis is associated with $48.0 \%$, cervical growth $8.0 \%$, endocervical polyp $2.0 \%$, cervical erosion $4.0 \%$, cervical tear $2.0 \%$, other causes associated like uterovaginal prolapse $4.0 \%$ (Table 4 ).

Table 4: Per Speculum Examination Findings $(\mathbf{n}=\mathbf{5 0})$

\begin{tabular}{lcc}
\hline Examination finding & Frequency & Percentage \\
\hline Chronic cervicitis & 24 & 48.0 \\
Cervical growth & 04 & 8.0 \\
Endocervical polyp & 01 & 2.0 \\
Cervical tear & 01 & 2.0 \\
Others & 02 & 4.0 \\
No positive findings & 18 & 36.0 \\
Total & $\mathbf{5 0}$ & $\mathbf{1 0 0 . 0}$ \\
\hline
\end{tabular}

Among 50 cases, there are clue cells in $12.0 \%$, Candida albicans in $10.0 \%$, Trichomonas vaginalis in $10.0 \%$ of cases (Table 5).

Table 5: Microscopic Examination Findings of Saline Preparation of Vaginal Discharge

\begin{tabular}{lcc}
\hline Examination finding & Frequency & Percentage \\
\hline Clue cells & 06 & 12.0 \\
Candida albicans & 05 & 10.0 \\
Trichomonas vaginalis & 05 & 10.0 \\
Normal study & 34 & 78.0 \\
Total & $\mathbf{5 0}$ & $\mathbf{1 0 0 . 0}$ \\
\hline
\end{tabular}

During pap's smear, inflammatory cell was detected in $68.0 \%$ cases, squamous metaplasia was in $12.0 \%$ and malignant cell in $8.0 \%$ cases. Normal study was found in $12.0 \%$ (Table 6).

Table 6: Pap's smear report of the study subjects $(n=50)$

\begin{tabular}{lcc}
\hline Pap's Smear Findings & Frequency & Percentage \\
\hline Inflammatory cell & 34 & 68.0 \\
Squmous metaplasia & 06 & 12.0 \\
Malignant cell & 04 & 8.0 \\
Normal study & 06 & 12.0 \\
Total & $\mathbf{5 0}$ & $\mathbf{1 0 0 . 0}$ \\
\hline
\end{tabular}


Whiff test was positive in $22.0 \%$ cases Whiff test is positive in both trichomoniasis and bacterial vaginosis. Cervical biopsy revealed carcinoma of cervix in $8.0 \%$ of cases. Regarding ultrasonogram of lower abdomen, majority shows normal finding and features of pelvic inflammatory disease (PID) in $48.0 \%$ cases (Table 7 ).

Table 7: Findings of different Investigations

\begin{tabular}{lccc}
\hline $\begin{array}{l}\text { Type of } \\
\text { Investigation }\end{array}$ & Positive & Negative & Total \\
\hline Whiff test & $11(22.0)$ & $39(78.0)$ & $50(100.0)$ \\
Cervical Biopsy & $4(8.0)$ & $46(92.0)$ & $50(100.0)$ \\
USG for PID & $24(48.0)$ & $26(52.0)$ & $50(100.0)$ \\
\hline
\end{tabular}

*USG=Ultrasonography

*PID=Pelvic Inflammatory Disease

*Figure within parenthesis indicates percentage

\section{Discussion}

Vaginal discharge is a common presenting symptom seen by doctors in gynaecological clinics ${ }^{6}$. Vaginal discharge may be physiological or pathological. Although abnormal vaginal discharge often prompts women to seek treatment, causes should be evaluated properly.

There are studies regarding the causes of vaginal discharge. Mitchell ${ }^{6}$ has found that vulvovaginal candidiasis, bacterial vaginosis and Trichomoniasis are the commonest infective cause of vaginal discharge $e^{6,13}$. In this study, cervical causes were associated in $64.0 \%$ of patients with vaginal discharge. Out of these, cervicitis is associated with $48.0 \%$, cervical erosion $4 \%$, and endocervical polyp $2.0 \%$, and cervical tear $2.0 \%$, carcinoma of cervix $8.0 \%$. Candidiasis $10.0 \%$, Trichomoniasis $10 \%$, bacterial vaginosis $12.0 \%$ are infective cause of vaginal discharge in this study but Yusuf et $\mathrm{al}^{13}$ showed that vaginal candidiasis $(53.6 \%)$ is the commonest cause of abnormal vaginal discharge in sexually active women $^{13}$. Nadira ${ }^{7}$ study in Bangladesh showed that PID is associated with vaginal discharge which also has similarity with this study. There is similarity between that studies conducted by $\mathrm{Shah}^{8}$ in India with this study.

All women were married which has an impact on the occurrence of vaginal discharge with active sexual life, which was also shown in another study done by Rice and schachter ${ }^{9}$. It is common in 25-35 years of age. In this study, majority, $60.0 \%$ are illiterate. It is the lack of education which makes the women ignorant about the fact that their sufferings are preventable by safe sexual practices, child birth and abortion and adoption of contraception.

Regarding previous pregnancy termination events, 52.0\% had history of MR or unsafe abortion, $34.0 \%$ had puerperal sepsis. This study therefore showed that in developing countries, the majority of cases were older parous women while in developed countries the majority were younger nulliparous women as shown by Mitchell ${ }^{6}$ study.

Regarding the different methods of contraception, present study showed that most $(40.0 \%)$ were nonusers and it was due to the fact that acceptance and sustained use of family planning methods were low in many parts of this country. On the other hand, most frequently used contraception is combined oral contraceptive pill $(20.0 \%)$ which may be associated with cervical erosion causing abnormal vaginal discharge ${ }^{7}$.

A limited number of investigations were done. Routine blood examination showed anaemia in $20.0 \%$ of cases, leucocytosis in $18.0 \%$ which may be due to super imposed active infection on chronic changes. Among all patients $22.0 \%$ had raised ESR which may be due to presence of a chronic inflammatory disease. It is rare to isolate the causative organism from the endocervical swab and high vaginal swab. Whiff test was positive in $12.0 \%$ cases. Microscopic exam of saline preparation of vaginal discharge revealed clue cells in $12.0 \%$, Candida albicans in $10.0 \%$ and Trichomoniasis in $10.0 \%$ of cases $^{13}$.Many women were self diagnose and self treat episodes of vaginal discharge with over the counter treatment $\&$ subsequently present with a persistent vaginal discharge when microbiological diagnosis may not be possible.

Pap's smear revealed normal study in $12.0 \%$, inflammatory cell in $68.0 \%$ squamous metaplasia in $12.0 \%$, malignant cell in $8.0 \%$ cases. Cervical biopsy revealed carcinoma of cervix in $8.0 \%$ cases. Regarding ultra sonogram of lower abdomen, majority showed normal finding and features of PID in $48.0 \% \operatorname{cases}^{15}$.

The study was carried out in the outpatient department of Obstetrics and Gynaecology, Dhaka Medical College Hospital on a small number of cases. So the results may not represent the overall situation in Bangladesh. Berksonian bias cannot be ruled out in this study.

\section{Conclusion}

Abnormal vaginal discharge has a relationship with pelvic inflammatory disease. It is common in women who have undergone unsafe abortion and MR. It is also most commonly seen in regular OCP user. Underlying cervical pathologies are cervicitis, carcinoma of cervix, cervical erosion, cervical tear, endocervical polyp.

\section{References}

1. Dutta DC, Text Book of Gynaecology, 4th edn., (New Central Book Agency, Kolkata), 2007, 503- 5

2. Ashrafunnessa. HPV in cervical cancer in Bangladesh. Bangladesh J Obstet Gynaecol, 2006;21(2):51-57

3. Bhatla N. Vaginal discharge. In: Jeffcoate's Principles of Gynaecology; 6th ed.2001;600-4

4. Arulkumamaran S, Symonds IM, Fowlie A. Oxford Handbook of Obstetrics \& Gynaecology; 2004;63:550-3

5. Decherney AH, Nathan L. Benign Disorders of the Vulva \& Vagina. In: Current Diagnosis \& Treatment in Obstetrics \& Gynecology; 10th ed.2007; 37:598- 603

6. Mitchell H. Vaginal discharge: Causes, diagnosis \& treatment. BMJ 2004;328:1306-1308

7. Nadira S. Chronic Pelvic Inflammatory Disease in GOPD of DMCH [FCPS Dissertation]. BCPS, Dhaka, Bangladesh; 2005

8. Shah HN, Patel S, Nagpal S. Pelvic inflammation (a study of 800 cases). J Obstet Gynaecol India 1978;28(3):429 
9. Rice PA, Schachter J. Pathogenesis of pelvic inflammatory disease. JAMA 1991; 266: 2587-93

10. Report of a RCOG meeting. Br J Obstet Gynaecol 1995; 102: 424-6

11. Faudes A. Reproductive tract infection. Intern J obstet Gynecol 1994;

$46 ; 181-7$

12. Mahnmud EA, Sueusson LO. Anti-chlamydial activity of vaginal secretion. Am J Obstet Gynecol 1995; 172: 1268-7

13. Yusuf MA, Chowdhury M, Islam KMS, Eva EO, Sharif AR, Rahman $\mathrm{MK}$, et al. Common microbial aetiology of abnormal vaginal discharge among sexually active women in Dhaka, Bangladesh. South East Asia
Public Health 2011;1:35-39

14. Pradhan N, Girik K, Rana A. Cervical cytology study in unhealthy and healthy looking cervix. N J Obstet Gynaecol 2007; 2(2):42-47

15. Eckert LO, Lentz GM. Infections of the lower genital tract: Vulva, vagina, cervix, toxic shock syndrome, HIV infections. In: Katz VL, Lentz GM, Lobo RA, Gershenson DM, eds. Comprehensive Gynecology. 5th ed. Philadelphia, Pa: Mosby Elsevier; 2007:chap 2

16. Zeimet A, McBride DR, Basilan R, Roland WE, McCrary D, Hoonmo K. Infectious diseases. In: Rakel RE, ed. Textbook of Family Medicine. 8th ed. Philadelphia, Pa:Saunders Elsevier; 2011: chap 16 